\title{
Relações e Estratégias de (Des)envolvimento Rural: políticas públicas, agricultura familiar e dinâmicas locais no município de Espera Feliz (MG)
}

\author{
Márcio Gomes da Silva ${ }^{1}$, Marcelo Miná Dias² e Sandro Pereira Silva ${ }^{3}$
}

Resumo: Este texto apresenta a análise das relações estabelecidas entre organizações de agricultura familiar e políticas públicas de desenvolvimento rural a partir de uma pesquisa realizada no município de Espera Feliz (MG). Constatou-se que inserção da "agricultura familiar" na agenda governamental provocou mudanças na atuação do Sindicato dos Trabalhadores Rurais (STR) de Espera Feliz, com a adoção de dispositivos coletivos utilizados pelos agricultores como estratégia de ação coletiva. Esses dispositivos sofreram adaptações em suas regras de reciprocidade, passando a constituir estruturas institucionais formalizadas. A partir do acesso a determinadas políticas públicas, criaram-se aproximações com mediadores sociais com vistas a potencializar as estratégias desenvolvidas pelas organizações locais. Essa relação torna-se conflituosa na medida em que há divergência das orientações coletivas para o desenvolvimento. As relações estabelecidas e analisadas puderam ser caracterizadas como relações de complementaridade, de dominação normativa e de dificuldades e tensões. Nesse conjunto de relações, forjaram-se aproximações entre as organizações e mediadores sociais que atuam no município.

Palavras-chaves: Desenvolvimento rural, políticas públicas, agricultura familiar, mediadores sociais, dominação normativa.

Abstract: This paper presents the analysis of the links between family farming organizations and rural development policies. The research was conducted in the municipality of Espera Feliz (MG). The results demonstrate that the adoption of family farm as an issue in public agenda was responsible for important changes in the performance of the Rural Workers Union (STR) of Espera Feliz with the adoption of collective devices used by farmers as a strategy for collective action. This organization adopted collective devices which began to

1. Departamento de Educação da Universidade Federal de Viçosa (DPE-UFV). Professor. E-mail: marcio.gomes@ufv.br

2. Departamento de Economia Rural da Universidade Federal de Viçosa (DER-UFV). Professor. E-mail:minad@ufv.br

3. Instituto de Pesquisa Econômica Aplicada (IPEA). Técnico de Planejamento e Pesquisa. E-mail: sandro.pereira@ipea.gov.br 
be used by farmers as a strategy for collective action. It was possible to observe that these collective devices have undergone adjustments to their rules of reciprocity, constituting formalized institutions. Given the access to certain public policies, approaches with social mediators were created in order to optimize strategies developed by local organizations. This relationship, which becomes conflicting as there are divergences of collective orientations for development, can be classified as a relation of complementarity, normative domination or difficulties and tensions. In this set of relations, approximations between organizations and social mediators who work advising the farmer's organizations are built up.

Key-words: Rural development, public policy, family farming, social mediators, normative domination.

Classificação JEL: Z13.

\section{Introdução}

O conceito de agricultura familiar, que ganhou espaço no debate social e político brasileiro nos anos 1990, surgiu sob a perspectiva de que o meio rural brasileiro abriga inúmeras formas de organização social baseadas na produção familiar e com forte imbricamento nas economias locais, definidas muitas vezes por seu enraizamento territorial e histórico (agricultores tradicionais de pequena produção, comunidades indígenas e quilombolas, ribeirinhos, assentados de reforma agrária etc.). Essas famílias, negligenciadas historicamente pela ação do poder público, têm demandas de bens e serviços públicos diferenciados, da mesma forma que apresentam ligações de diversos tipos com o ambiente urbano em seus municípios (SILVA, 2012; SOUZA, SILVA e SILVA, 2012).

À medida que esse conceito foi se fortalecendo, tanto no meio acadêmico quanto nas organizações representativas dos próprios agricultores, o Estado brasileiro passou a ser pressionado a garantir, por meio de políticas públicas, o reconhecimento da agricultura familiar enquanto um segmento socioprodutivo importante para o desenvolvimento rural e também o atendimento de demandas produtivas e sociais (KAGEYAMA, 2008). Além disso, observa-se, desde o retorno do período democrático no País, a emergência de diferentes organizações da sociedade civil, tais como ONGs, associações e cooperativas, ampliando a diversidade de formas de expressão em torno de novos projetos de desenvolvimento. Essas organizações colocam-se, muitas vezes, na posição de mediação entre o Estado e as práticas organizativas da população, passando a fazer parte de estruturas de gestão e governança das políticas públicas.

É nesse contexto que surgem, no País, nos últimos anos, políticas públicas diferenciadas que inserem a temática do desenvolvimento rural na agenda governamental, tendo a agricultura familiar como foco das intervenções. $\mathrm{O}$ marco institucional dessa novidade foi o lançamento do Programa Nacional de Fortalecimento da Agricultura Familiar (Pronaf), em 1996, demarcando uma diferenciação nas até então predominantes políticas agrícolas de fomento à agricultura. Trata-se de um contexto de inovação institucional nas políticas públicas de desenvolvimento dos espaços rurais, que passaram a ser executadas, geralmente, por meio de parcerias entre organizações governamentais e não governamentais, promovendo interações com as dinâmicas locais (SILVA, 2011).

Entretanto, esse tipo de interação gera uma série de questões à produção do conhecimento. Em que medida o surgimento de organizações da agricultura familiar ocorre por uma real necessidade social de organização econômica coletiva manifestada localmente? Até que ponto elas 
emergem por influência ou determinação das normativas em que se fundamentam as políticas públicas de desenvolvimento rural? Para compreender o conjunto de interações entre políticas públicas e dinâmicas locais, a análise das dinâmicas desencadeadas em municípios com forte presença da agricultura familiar pode apresentar ensinamentos importantes.

Nesse sentido, este trabalho buscou caracterizar e analisar os processos estabelecidos entre as organizações de agricultura familiar do município de Espera Feliz (MG) e o acesso e implementação de políticas públicas de desenvolvimento rural. Mais especificamente, dadas as especificidades deste texto, focou-se na identificação e análise das relações entre as ações dessas organizações e as mudanças verificadas na orientação das políticas públicas de desenvolvimento rural a partir da década de 1990.

A escolha do município de Espera Feliz como base empírica de análise está diretamente relacionada aos processos de desenvolvimento rural estabelecidos no município durante a década de $1990^{4}$. Com o objetivo de identificar as relações estabelecidas entre o contexto foi utilizada uma combinação de métodos e instrumentos de pesquisa: revisão bibliográfica sobre temas como sindicalismo, desenvolvimento rural e políticas públicas; entrevistas semiestruturadas junto às lideranças envolvidas com as organizações em questão; análise documental com base em atas de assembleias e relatórios de planejamento do Sindicato de Trabalhadores Rurais (STR) de Espera Feliz; e observação participante durante reunióes e atividades do cotidiano das organizações.

4. O município de Espera Feliz (MG) está localizado na região norte da Zona da Mata Mineira e tem área de $326,4 \mathrm{~km}^{2}$. A população total é de 20.835 habitantes, sendo que aproximadamente $40 \%$ vive em áreas rurais, com o predomínio de pequenas propriedades, o que demonstra a importância da agricultura para o município. No período de 1991 a 2000, o Índice de Desenvolvimento Humano Municipal (IDH-M) cresceu 12,9\%, passando de 0,620 em 1991 para 0,700 em 2000. Apesar desse crescimento, o IDH do município ainda está abaixo do estadual, que é de 0,773 , sendo considerada como região de médio desenvolvimento humano (ADH, 2000).
A metodologia baseou-se em um conjunto de métodos de investigação. Inicialmente, foram realizadas entrevistas semiestruturadas ${ }^{5}$ junto às lideranças envolvidas com as organizações em questão e que estabeleceram relações nos cenários além do local, criando vínculos com processos e discussões nacionais. A partir das entrevistas com este público, foi possível analisar como as organizações surgiram e quais as relações que as levaram a se envolver em determinados processos, bem como identificar quais foram (e ainda são) as ações desenvolvidas pelas organizações locais por intermédio do acesso a políticas públicas específicas. Por meio das entrevistas também foi possível identificar quais mediadores sociais estavam envolvidos com as organizações e identificar os projetos e programas voltados para a agricultura familiar em curso no STR. A pesquisa documental ${ }^{6}$ foi utilizada para identificar a relação entre o contexto de atuação do STR e as mudanças na orientação das políticas públicas de desenvolvimento rural, com base nas atas de assembleias (de 2000 a 2005) e atas de reuniões de diretoria do STR (de 2003 a 2009). A análise destes documentos possibilitou identificar categorias que relacionam $\mathrm{o}$ contexto local de atuação do STR, em seus diferentes momentos históricos, com as mudanças no contexto das políticas públicas. Como complemento à análise documental foi realizada observação participante ${ }^{7}$ durante reuniões e atividades

5. As entrevistas semiestruturadas "partem de questionamentos básicos, apoiados em teorias e hipóteses, que interessam à pesquisa, e que, em seguida, oferecem amplo campo de interrogativas, fruto de novas hipóteses que vão surgindo à medida que se recebem as respostas do informante. Desta maneira, o informante, seguindo espontaneamente a linha de seu pensamento e de suas experiências dentro do foco principal colocado pelo investigador, começa a participar na elaboração do conteúdo da pesquisa" (TRIVINOS, 1987, p. 146).

6. "[...] a pesquisa documental consiste em saber esclarecer a especificidade e o campo de análise de conteúdo. Seria um conjunto de operações visando representar o conteúdo de um documento de forma diferente. Seu objetivo consiste na reapresentação condensada da informação" (MARCONI et al., 2006, p. 29).

7. Esta técnica foi utilizada por fornecer um conjunto de descrições detalhadas do objeto em questão, evidenciando conflitos e problemas que possibilitem a compreensão das organizações em análise. 
232 - Relações e Estratégias de (Des)envolvimento Rural: políticas públicas, agricultura familiar e dinâmicas locais no município de Espera Feliz (MG)

cotidianas das organizações analisadas. Durante o trabalho de campo, acompanhou-se a rotina de atendimento aos agricultores, o que permitiu identificar parte das principais necessidades demandadas por estes junto ao STR. Os aspectos históricos de constituição do sindicalismo rural no Brasil, as disputas e mobilizações realizadas nesse contexto de constituição da agricultura familiar enquanto agenda de políticas públicas foram identificados a partir de pesquisa bibliográfica sobre o tema.

\section{Políticas públicas e agricultura familiar}

A agricultura familiar corresponde a um conjunto de relações complexas em que a propriedade e o trabalho estão intimamente ligados à família. Nesse contexto, existe uma formação social heterogênea, caracterizando-se enquanto agricultura que "contém nela mesma a diversidade" (LAMARCHE, 1993). Essa diversidade se configura em diferentes relações com o mercado e em representações e modos de vida que se apresentam em contextos heterogêneos específicos. No Brasil, essa forma de agricultura estabeleceu-se à margem de uma estrutura de grandes propriedades, a qual o Estado, a partir de suas políticas agrícolas, procurou modernizar e garantir sua reprodução social vinculada à dinâmica do desenvolvimento capitalista. Essa atuação do Estado reflete, em grande medida, as relações predominantes dentro de sua própria estrutura, delimitando uma arena de disputas com correlações de forças distintas, que defendem concepções diferenciadas sobre o desenvolvimento rural (WANDERLEY, 2009).

Atualmente, a agricultura familiar é parte da agenda de políticas públicas de desenvolvimento rural, tendo como marco de entrada no cenário político o Pronaf, instituído em 1996. Para os movimentos sociais ligados a questões rurais, a agricultura familiar passou a ser um componente unificador de diversas categorias sociais que se identificavam ou eram nomeadas por outros ter- mos. Entretanto, a adoção do termo como assunto de políticas públicas perpassa um período histórico de conflitos no meio rural. Esses conflitos permearam a emergência de organizações dos trabalhadores rurais, como as Ligas Camponesas, nos anos 1960, ou mesmo no surgimento dos sindicatos de trabalhadores rurais, organizações responsáveis por evidenciar as carências dessa categoria social e exercer pressão frente ao Estado para o reconhecimento desse público.

Uma agenda de políticas públicas é definida a partir da identificação dos problemas, de sua divulgação e da produção de informações que demonstram falhas na política atual (SOUZA, 2006). Sendo assim, para a compreensão do surgimento da agricultura familiar na agenda das políticas de desenvolvimento rural é necessário compreender as relações do contexto macroeconômico em que emergem tais políticas, bem como as relações entre os "agentes definidores" das políticas, dentre eles, organizações da sociedade civil, movimentos sociais, movimento sindical rural, organizações não governamentais (ONGs), elites econômicas, dentre outros, no contexto de disputas decorrentes das políticas agrícolas no Brasil (BONETTI, 2007).

A emergência da agricultura familiar como componente da agenda das políticas públicas de desenvolvimento rural no Brasil está relacionada a um conjunto de mudanças macroeconômicas ocorridas no final da década de 1990 que afetaram a política agrícola diretamente, provocando redução da oferta de crédito rural, eliminação de subsídios e desregulamentação do mercado agrícola interno. Outras variáveis explicativas, já nos anos 1990, referem-se ao processo de desestatização de empresas públicas, início do processo de abertura econômica e desmantelamento dos órgãos públicos de pesquisa e extensão rural. Esse cenário de ajuste estrutural no Brasil provocou reações diversas nas mais distintas formas de organizações no meio rural (CORDEIRO et al., 2003).

Foi nesse contexto que a expressão agricultura familiar ganhou aceitação e unificou o discurso dos "pequenos produtores" junto à conjuntura das tensões provocadas entre trabalho não assa- 
lariado e trabalho assalariado. Ou seja, foi a partir desse cenário que os movimentos sociais ligados ao campo unificaram, na expressão "agricultura familiar", uma série de segmentos sociais, como pequenos produtores, arrendatários, parceiros, sitiantes, moradores etc. Essas categorias, a partir de então e de forma crescente, passaram a se identificar publicamente como "agricultores familiares". Em relação ao Estado e suas políticas públicas, essa expressão foi legitimada com a criação do Pronaf (SCHNEIDER, 2003).

Com a nova conjuntura estabelecida a partir da década de 1990, os sindicatos de trabalhadores rurais iniciam um processo de mudança nas bandeiras históricas de luta no campo. O que até então eram reivindicações voltadas para a reforma agrária e salvaguarda dos direitos trabalhistas foi modificado para a construção de um projeto alternativo de desenvolvimento ${ }^{8}$, pautado no fortalecimento da agricultura familiar (FAVARETO, 2006).

A emergência da agricultura familiar como tema e identidade sociopolítica provocou também a constituição de novas organizações representativas a nível nacional. Além da Confederação Nacional dos Trabalhadores da Agricultura (Contag), criada em 1963 e que continua sendo a principal central sindical de trabalhadores rurais no País, outras organizações, como a Federação dos Trabalhadores da Agricultura Familiar (Fetraf) e o Movimento dos Pequenos Agricultores (MPA), foram constituídas a partir

8. Este projeto político torna-se evidente em um documento publicado por uma organização sindical no início dos anos 1990: “Um projeto Alternativo de Desenvolvimento que garanta a viabilização da Agricultura Familiar implica: a) um novo modelo tecnológico que leve em conta as questões sociais e ecológicas da produção agrícola; b) novas formas de organização da produção, comercialização, beneficiamento da produção e abastecimento; c) reforma agrária enquanto instrumento para transformação do atual modelo de desenvolvimento da agricultura brasileira; d) política agrícola diferenciada para o pequeno agricultor; e) pesquisa e extensão rural voltados para o interesse dos trabalhadores e f) construir as bases culturais de um desenvolvimento alternativo, resgatando valores como a solidariedade, a cooperação e estabelecendo uma nova relação homem natureza" (Departamento Estadual de Trabalhadores Rurais do Rio Grande do Sul - DETR-RS, 1992 apud NUNES, 2007). do fim dos anos 1990, garantindo representação em vários estados. A partir de então, são inseridas na pauta do sindicalismo de trabalhadores rurais outras questões, tais como desenvolvimento sustentável e economia solidária (SILVA e NAGEM, 2012). Esses temas passam a fazer parte das finalidades dessas entidades, que explicitam a intenção de suas ações para além da organização sindical, adentrando nas esferas da organização da produção, da cooperação, desenvolvimento de práticas associativas, a partir de uma concepção de desenvolvimento que busca afirmar como premissa a sustentabilidade, a solidariedade e a democracia social e política (RODRIGUES, 2004).

É nesse cenário de contestação política, resultado das críticas à modernização da agricultura e do difusionismo como marca da prática dos serviços públicos de extensão rural, que as organizações de movimentos sociais do campo engendraram disputas políticas em torno de modelos alternativos de produção e desenvolvimento. Neste contexto, as ONGs, junto aos movimentos sociais, foram fundamentais na luta pelos direitos dos trabalhadores rurais e na problematização dos modelos convencionais de desenvolvimento. E o fizeram a partir do enfrentamento de condições adversas vivenciadas, organizando-se localmente, tanto frente às imposições do poder estatal centralizado quanto, em outros casos, à própria ausência do Estado. Nesse encontro entre ONGs e movimentos sociais, articularam-se outros modos de promoção do desenvolvimento, para os quais a participação política dos envolvidos ganhou papel de destaque em relação aos processos de intervenção propostos (DIAS, 2004).

Nota-se, então, a inserção de novos temas vinculados à ideia de desenvolvimento rural, tais como: a participação, a questão ambiental e a discussão acerca de processos de desenvolvimento sustentáveis. Esse ideário foi amplamente compartilhado nas redes sociais de interação que uniam os agricultores familiares, ao menos aqueles que se organizavam e passavam a agir coletivamente. O desenvolvimento rural era re-significado não apenas teoricamente, mas passava a compor uma agenda política, isto é, 
234 - Relações e Estratégias de (Des)envolvimento Rural: políticas públicas, agricultura familiar e dinâmicas locais no município de Espera Feliz (MG)

configurava tanto uma pauta de reivindicações, apresentadas sistematicamente ao Estado, como um conjunto de orientações às práticas dos próprios agricultores familiares e de suas organizações. $\mathrm{O}$ fomento à produção já não era suficiente. A demanda era por melhores condições de vida e bem-estar das famílias no campo, aliada ao incremento da renda e, ao menos no nível do discurso produzido, a outro estilo de relacionamento com as variáveis ambientais dos processos produtivos.

Essas mudanças de concepção adentravam os contextos locais. Os eventos que reuniam agricultores de todo o País e a ação dos mediadores difundiam concepções e novas leituras dos processos. As localidades eram influenciadas pelas mudanças nas orientações que chegavam principalmente por meio daqueles que assessoravam a organização dos agricultores familiares.

No município de Espera Feliz (MG) não foi diferente. A história da mobilização e organização dos agricultores familiares do município passa a ser contada, a seguir, pelos protagonistas do processo?.

\section{A constituição do STR de Espera Feliz}

Sob a trajetória do Sindicato dos Trabalhadores Rurais (STR) de Espera Feliz são identificados dois contextos históricos distintos. O primeiro deles refere-se à resposta à exploração, ou seja, ao surgimento do sindicato como forma de conter a exploração dos patrões frente aos chamados "boias-frias" e de resguardar a estes os direitos trabalhistas. O segundo é o contexto de inserção da agricultura familiar nas ações do sindicato, provocando mudanças na sua atuação, além do

9. Os depoimentos apresentados a seguir foram obtidos a partir de entrevistas em profundidade com os atores sociais diretamente envolvidos com o processo de constituição e ação do STR de Espera Feliz. Optamos, junto aos entrevistados, por resguardar suas identidades. Este procedimento torna-se necessário para evitar eventuais constrangimentos aos envolvidos. Entende-se que o resguardo da identidade dos autores das falas não compromete a legitimidade do conhecimento produzido a partir de seus depoimentos, que, é importante afirmar, torna público um processo marcado por divergências e conflitos. surgimento de outras organizações em uma conjuntura de políticas públicas com agenda específica, relacionado a questões de organização econômica na agricultura familiar.

O primeiro contexto foi marcado pelos trabalhos das Comunidades Eclesiais de Base (CEBs), grupos ligados à Igreja Católica, que se propunham a formar lideranças com uma orientação mais atuante frente aos conflitos que permeavam as relações agrárias no Brasil. Em Espera Feliz, esse trabalho das CEBs estava vinculado a ações ordenadas denominadas de "Projeto de Deus". Tratava-se de reuniões de caráter reflexivo em torno do evangelho, porém vinculadas a problemas concretos existentes nas comunidades rurais. A partir dessas reuniões emergiram as motivações de constituição do STR, em 1986, com um quadro de sócios na ordem de 800 trabalhadores rurais locais.

Dentre os conflitos referentes aos direitos desses trabalhadores, tem-se como prioridade o controle sobre os mecanismos de acesso aos serviços públicos de saúde; vinculado à posse da carteirinha do Instituto Nacional de Assistência Médica da Previdência Social (Inamps). A posse dessa carteirinha por parte do meeiro ou do trabalhador rural só era possível a partir da assinatura do patrão. Sendo assim, o mediador entre o serviço de saúde e os trabalhadores rurais era o patrão. A partir da fundação do STR, o sindicato passou a ser o mediador, o responsável pelo acesso desses trabalhadores aos serviços de saúde; e passa, a partir de então, a arrebanhar um número grande de sócios, causando desconforto nas estruturas de dominação dos fazendeiros frente aos trabalhadores e meeiros da época. Como represália, aqueles que aderiam ao sindicato tinham os contratos de arrendamento desfeitos pelos proprietários das terras.

Os agricultores não sindicalizados, aliados dos fazendeiros, espalhavam rumores de que o sindicato traria miséria para Espera Feliz. A perseguição se estendia aos espaços de sociabilidade das lideranças: desde uma partida de futebol até as relações de namoro nas comunidades eram 
afetadas pelo fato de ser parte do corpo diretivo do STR.

Nesse período, a assessoria aos trabalhos do STR era feita pela Comissão Pastoral da Terra (CPT), também ligada à Igreja Católica, que promovia desde a formação sociopolítica de lideranças até a assessoria jurídica referente às causas trabalhistas. Esse trabalho da CPT ocorria a nível nacional em torno dos conflitos no campo, tendo uma orientação crítica para as práticas sindicais que se estabeleciam até então no Brasil, qual seja, de desmobilização estrutural provocada pelo Funrural ${ }^{10}$ e a ação estrita na execução de políticas de previdência pelos STR (BONI, 2004). Os conflitos e o desconforto causado em outros segmentos sociais do município resultaram em dificuldades para o início do funcionamento do STR, o que exigia de seus participantes um caráter de doação e voluntariedade, como afirmou um dos sócios-fundadores sobre os seminários para a sua constituição: “[...] não recebíamos nada, não havia liberação, não recebíamos dia de serviço, levávamos as coisas para cozinhar lá [nos Seminários]".

O segundo contexto teve início a partir de agendas de atuação vinculadas a questões produtivas e econômicas da agricultura familiar e ao acesso a políticas públicas de desenvolvimento rural. De acordo com Favareto (2006), foi na década de 1990 que o sindicalismo rural modificou antigas bandeiras de luta, assumindo, gradativamente, um projeto alternativo de desenvolvimento rural, ancorado na expansão e fortalecimento da agricultura familiar. Essas mudanças conjunturais refletiram na atuação do STR de Espera Feliz, sendo inseridas em seus trabalhos questões produtivas, de comercialização,

10. No âmbito do Estatuto do Trabalhador Rural (ETR), de 1963, foi criado o Fundo de Previdência e Assistência ao Trabalhador Rural (Funrural), que, devido a uma série de dificuldades de implementação, "não passou de uma carta de intenção, sem nenhuma utilidade prática" (FERRANTE, 1976, p. 191). Após uma série de alterações posteriores, foi instituído o Programa de Assistência ao Trabalhador Rural (Pró-Rural), regulamentado por meio de Lei Complementar em 1972, que prevê a aposentadoria por velhice, invalidez, bem como uma série de benefícios assistenciais e de saúde, cuja gestão ficaria a cargo do Funrural. do crédito, mais especificamente para atender a demandas apresentadas pela agricultura familiar do município. A partir do relato de um agricultor é possível identificar essa mudança ocorrida em nível local.

"Quando se cria o STR na década de 1990, o
objetivo principal era o enfrentamento com
o patronato. Aqui tinha uma relação muito
conflituosa com o patrão, e o sindicato começa
a assumir essa causa. Em um determinado
momento começa a surgir a necessidade da
venda de alguns produtos. Aqui é uma rea-
lidade muito cruel com essa coisa dos atra-
vessadores, muita gente se enriqueceu aqui
comprando o café na árvore. Em algumas pro-
priedades o meeiro vendia até mesmo para o
patrão".

Na experiência dos atores políticos que se filiavam ao STR de Espera Feliz há um processo particular de ocorrência de desencontros, estranhezas e resistências relacionadas ao reconhecimento dos agricultores como sujeitos de direitos. O "estranho", na acepção de Martins (1993), era o sujeito do processo de apagamento das singularidades locais historicamente estabelecidas. Era o patrão e era o atravessador, em um primeiro momento; e o Estado, a seguir, sujeito da modernização agrícola e suas políticas públicas. Deste modo, busca-se afirmar uma visão de desenvolvimento que, de diversas formas, promovia mudanças que se contrapunham às relações sociais, aos valores e regras vigentes. Na medida em que foram ocorrendo essas mudanças, ocorreu também uma aproximação com outros mediadores sociais importantes, tais como o Centro de Tecnologias Alternativas Zona da Mata (CTA-ZM) e a Universidade Federal de Viçosa (UFV), que propiciaram a inserção de temáticas novas para os agricultores do município, tais como meio ambiente, comercialização, cooperativismo e associativismo. Estes novos "estranhos" alinhavam-se à luta dos agricultores em sua busca por direitos e afirmação de sua singularidade. No entanto, contraditoriamente, também afirmavam o projeto modernizante que o Estado buscava instituir. 
236 - Relações e Estratégias de (Des)envolvimento Rural: políticas públicas, agricultura familiar e dinâmicas locais no município de Espera Feliz (MG)

Sem a pretensão de estabelecer uma relação determinística e estruturante do contexto macro sobre as dinâmicas que ocorrem no nível local, tem-se, nesse período da década de 1990, no STR de Espera Feliz, a incorporação de temas relacionados à produção, à organização econômica e à agricultura familiar também na agenda das políticas públicas. Estes passam, em certa medida, a serem incorporados pelas organizações de agricultura familiar em nível local, seja em sua prática discursiva em espaços públicos, seja em sua prática em nível comunitário junto aos agricultores por elas atendidos. Um componente analítico que permite compreender parte dessa relação entre o contexto macro e o local é a presença dos mediadores sociais ${ }^{11}$.

Essa relação entre os mediadores sociais e as dinâmicas locais não estabelece, entretanto, uma relação causa-efeito, ou seja, os temas não começam a ser discutidos na escala local especificamente a partir do momento em que são estabelecidas relações com os mediadores sociais. Destarte, existe uma organização prévia sob a qual as relações externas incidem como complementaridade dessas ações locais, como podemos perceber na fala de um agricultor envolvido no processo.

"As coisas não caem do céu, elas surgem a partir da necessidade, e assim que o sindicato nasce a partir da necessidade, algumas coisas passam a surgir, como falei das bandeiras de luta, por exemplo, quando o sindicato soltou um boletim falando sobre a morte silenciosa por agrotóxico, já tinham várias denúncias de trabalhadores que estavam morrendo, morte de animais, de peixe, então, a luta contra os

11. Esses mediadores "servem de ligação entre os pequenos 'pedaços' socioeconômicos e culturais que são as comunidades, as associações e outros grupos, de uma parte, e o mercado (ou a economia internacionalizada) e o político (as representações políticas do social), de outra" (ALMEIDA, 1999, p. 23). Para Neves (2008, p. 174), "o termo mediação alude à conciliação diante de divergências ou da intervenção de outrem com o objetivo de propor o acordo ou o compromisso. Portanto, refere-se à objetivação de sistemas de regulação instituídos para reduzir a dissonância entre visões de mundo e formas de comportamento de distintos segmentos constitutivos das sociedades complexas". agrotóxicos também vem de uma necessidade, de morte de pessoas e de animais. A questão da agroecologia é fruto desse trabalho, que aí os grupos começam a buscar as suas próprias alternativas para não usarem agrotóxicos, e com o tempo, o fato de a gente trabalhar em parceria com o CTA, que tem esse objetivo de fazer a assessoria na área de agricultura familiar na região, aos poucos foi introduzindo a questão da agroecologia na região. O CTA deu muita contribuição na luta contra o agrotóxico. Percebemos que essa discussão estava conectada na região, e a partir dessa discussão da agroecologia, surgem outros parceiros. A Associação Regional, tratando a questão da comercialização, e o CTA por ser uma entidade conhecida a nível de (sic) Estado, cria esse vínculo para o sindicato ir conhecendo outras experiências de lutas. Essa troca de experiência é muito importante para a região. Tem uma coisa importante que é bom relatar sempre que é sobre o fortalecimento do movimento sindical".

Percebe-se que, na década de 1990, há uma mudança no discurso, ou seja, o que até então tinha como componente discursivo o "bóia-fria", passa a ter como elemento constituinte o "agricultor familiar". A mudança de nomeação indica também uma mudança na prática cotidiana do sindicato. $\mathrm{O}$ discurso foi relacionado às novas representações políticas que emergem no sindicalismo rural brasileiro, agora com outra roupagem estampada pela agricultura familiar. A luta dos agricultores é, portanto, uma luta histórica pela terra e por direitos. Na década de 1990, os sujeitos políticos que se filiam ao STR de Espera Feliz direcionam a luta por direitos para o Estado e o acesso a políticas públicas, de modo que as mesmas, uma vez localmente apropriadas às singularidades historicamente instituídas e ao conteúdo da resistência política defendida pelo STR, se contraponham às transformações decorrentes da expansão das relações capitalistas de produção na agricultura.

A mudança de atuação do sindicato não se explica apenas pelas relações estabelecidas em termos nacionais, ou seja, pelas modificações em 
um campo político mais abrangente. Elas não foram condições sine qua non para a mudança de foco de atuação em Espera Feliz. Por meio das entrevistas realizadas, percebe-se que existiram outros fatores que contribuíram para que essa mudança se consubstanciasse.

"As políticas externas, a conjuntura do País de certa forma ajudou para essa mudança de público (trabalhador para agricultor familiar). O governo Lula também abriu muitas oportunidades para a agricultura familiar, a gente tem uma porção de questionamentos também porque sabemos que a agricultura convencional mecanizada ainda apropria a maior parte dos recursos que existem para a agricultura. A mudança não foi em função disso, essa foi uma das questões, mas o próprio sindicato, se formos ver o caso de Espera Feliz, a maioria das pessoas que estão lá são da agricultura familiar. Acho que se você não está presente dentro das estruturas, quem está lá acaba dando a direção, se for ver na maioria que está na direção ou é proprietário, filho de proprietário ou é um parceiro que está enquadrado dentro da agricultura familiar, quem é da direção do sindicato que é assalariado hoje? Não tem ninguém. Aos poucos as coisas foram saindo de pauta, porque as próprias pessoas que estavam lá dentro não puxavam. Não foi diferente da região, por que toda a região é marcada por essa questão da agricultura familiar dentro do sindicato. Porque na época que tinha toda a pressão pra cima da gente quem aguentou mais era quem tinha um pedaço de terra ou era filho de agricultor familiar".

Assim, as decisões e estratégias no sindicato eram elaboradas com o foco nos problemas do agricultor familiar, pois eram eles que compunham sua estrutura de direção. Esse fato ajuda a compreender as demandas relacionadas à comercialização e organização da produção que entram em pauta no STR, na medida em que passaram também a ser objeto de reivindicação de agricultores familiares em termos nacionais. Portanto, a relação entre aspectos conjunturais pelos quais atravessava o sindicalismo rural nacional, tais como a inserção da agricultura familiar e o sur- gimento de políticas específicas para esse segmento, e questões peculiares do sindicato em Espera Feliz, contribuíram para a mudança de sua atuação a partir da década de 1990. Tem-se, portanto, a expressão evidente da contradição e do descompasso entre o desenvolvimento capitalista (e os sujeitos que o promovem - os "estranhos" que chegam ao local) e, ao mesmo tempo, a resistência política pelos sujeitos de luta (agricultores e mediadores alinhados à sua causa).

\section{Políticas públicas e o surgimento de novas organizações}

O histórico de surgimento das organizações de agricultura familiar no âmbito do STR é um componente explicativo da relação entre as mudanças nas políticas públicas de desenvolvimento rural e as dinâmicas locais. O surgimento dessas organizações representa, neste estudo, uma evidência empírica de mudanças nas dinâmicas locais a partir do momento em que se modificam as orientações e as agendas das políticas públicas, incorporando temas como organização da produção e comercialização no dito "projeto alternativo de desenvolvimento".

O processo de organização econômica associativa em Espera Feliz é marcado pela criação da Associação dos Pequenos Produtores de Espera Feliz e Caiana (Apefec) no início da década de 1990. Essa é a primeira experiência de organização social com vistas à comercialização dos produtos da agricultura familiar no município. Essa experiência da Apefec se renovou em outro formato, em meados da década de 1990, agora sob a roupagem da agricultura familiar, passando a se denominar Associação Intermunicipal da Agricultura Familiar (Asimaf).

Dois fatos foram fundamentais para essa alteração. O primeiro, no plano local, é que havia um acúmulo de aprendizado coletivo ${ }^{12}$ acerca da prá-

12. De acordo com Sauborin (2009), o aprendizado coletivo é adquirido a partir do envolvimento mútuo e recíproco em uma experiência coletiva, nesse caso em questão, a construção associativa da organização econômica. 
238 - Relações e Estratégias de (Des)envolvimento Rural: políticas públicas, agricultura familiar e dinâmicas locais no município de Espera Feliz (MG)

tica associativa no município que possibilitou a constituição da Asimaf. O segundo, de influência externa, é que a mudança se inseriu no contexto de políticas públicas voltadas para a agricultura familiar.

O surgimento da Asimaf pode ser considerado parte de uma estratégia de constituição de mercados específicos para os produtos da agricultura familiar. Entende-se que o processo de organização econômica forjado pela associação foi no sentido de buscar autonomia, ou estabelecer o que Ploeg (2008) definiu como "circuitos

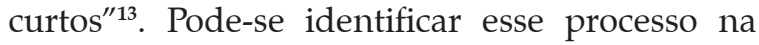
entrevista de um agricultor que participou do processo de constituição da Asimaf:

"A Asimaf foi criada com o objetivo de organizar a produção, e a partir daí, outras lideranças que vão surgindo no cenário começam a ocupar os espaços de discussão, e a gente foi dá conta de que a gente produzia, de que tínhamos muita produção, de que os agricultores precisavam de um espaço para, de uma forma mais justa, entrar no mercado, não no mercado convencional, mas um mercado solidário. Com a criação do mercadinho, começou a ser consolidada a economia solidária, que na verdade já existia no município, pois já realizávamos campos de sementes e consideramos isso economia popular solidária".

Percebe-se que, no processo de criação da Asimaf, existiam dispositivos coletivos sob os quais se edifica a formalização da organização econômica (campos de sementes citado na entrevista acima, por exemplo). Tem-se, assim, "a adaptação das formas e das regras de reciprocidade em estrutura institucional moderna e formalizada" (SABOURIN, 2009, p. 187).

Há uma nítida mudança na prática sindical a partir da emergência de novos temas e da consti-

13. Ploeg (2008) afirmou que, para enfrentar os mercados dominados pelos impérios alimentares, os agricultores passaram a diversificar os seus processos produtivos. Essa diversificação é combinada, frequentemente, com o processamento de produtos dentro das unidades agrícolas e com a construção de circuitos curtos de ligação entre estas e os consumidores. tuição de uma organização responsável por uma atividade econômica, como afirma um agricultor entrevistado: "é muito diferente o papel de ser sindicalista e de assumir um negócio, um comércio". Como resultado deste processo foi constituída em 2005 a Cooperativa de Produção da Agricultura Familiar e Solidária (Coofeliz), com o objetivo de promover a comercialização dos agricultores familiares que, até então, era realizada pela Asimaf. Sua constituição ocorreu em meio a uma mudança jurídica no novo Código Civil Brasileiro, que se deu em 2001, na qual as associações (como a Asimaf, por exemplo), passaram de "associações sem fins lucrativos", para "associações sem fins econômicos". Para além de uma alteração jurídico-normativa, essa mudança impôs limitações operacionais para a Asimaf. Ela não poderia mais emitir nota fiscal, por exemplo, o que inviabilizava sua função de intermediação comercial.

Outro incentivo para a constituição da Coofeliz surgiu em 2003, com o lançamento, pelo governo federal, do Programa de Aquisição de Alimentos (PAA) ${ }^{14}$. Sem a cooperativa formalizada, não seria possível o acesso ao PAA, tendo em vista que a Asimaf não possuía a personalidade jurídica apropriada. Tem-se, nesse caso, um ordenamento jurídico de regulamentação da organização econômica coletiva em termos formais. Essa formalização é uma exigência do PAA, provocando mudanças diretas na dinâmica social das organizações de agricultura familiar no município. Por outro lado, tem-se, no acesso à política pública, uma modificação dos dispositivos coletivos, o que até então tinha um caráter informal, baseado nas trocas (como no caso do banco de sementes), passa a ser formalizado como estratégia de estabelecer mecanismos de acesso. De

14. O PAA foi inserido pelo governo federal no Plano de Safra da Agricultura Familiar 2003/2004 como uma estratégia de realização da produção de alimentos básicos, oriunda da agricultura familiar, integrando política agrícola e de segurança alimentar e nutricional. Esse programa permite a compra pública de produtos de agricultores familiares, a preços estabelecidos pela Companhia Nacional de Abastecimento (Conab), com recursos do MDS e do MDA, para doação, merenda escolar ou formação de estoques (D'ÁVILA e SILVA, 2011). 
acordo com Sabourin et al. (2005, p. 299), essa relação do Estado, em termos de política pública, com as organizações locais, traz vantagens para ambos os lados, pois facilita o funcionamento e a reprodução desses dispositivos coletivos, no caso em questão a Coofeliz; e para o Estado, "cria uma verdadeira oportunidade de delegar serviços mediante uma política pública baseada em relações contratuais".

A partir da análise do surgimento da Asimaf e a evolução organizativa da associação em cooperativa, tem-se, então, um elemento importante referente às questões normativas, tanto no que se refere à mudança no Código Civil quanto à exigência de formalização para se estabelecer mecanismo de acesso ao PAA. Esse mecanismo possibilita a criação de uma primeira categoria analítica dessa relação entre política pública e as dinâmicas locais, denominada neste trabalho de dominação normativa ${ }^{15}$.

Esse processo de constituição da Coofeliz também pode ser visto como uma estratégia estabelecida pelo grupo de agricultores familiares vinculados ao STR de constituir uma organização com orientações mais próximas da ação coletiva ${ }^{16}$, ou seja, voltada para a agricultura familiar. O depoimento de um agricultor e dirigente sindical ilustra essa questão:

“Essa ideia da Cooperativa é uma ideia muito antiga na cabeça do povo de Espera Feliz. Na década de 1990, havia um grande império aqui que era a Cooparaiso e Coapav [Cooperativa do

15. Esse termo será usado neste estudo quando houver referência às exigências normativas estabelecidas pelo Estado para que os agricultores familiares possam ter acesso a alguma política pública. Dessa forma, é possível compreender o esforço que ocorre em termos locais e a mudança nos processos organizativos dos agricultores para "atender" as exigências colocadas por essas normas. O termo "dominação" reforça que, nessa relação, o poder normativo do Estado sobrepõe-se às dinâmicas locais. Na medida em que se procura o acesso a determinadas políticas, há um esforço, por parte das organizações de agricultura familiar, de criarem estratégias para se adequarem a esses mecanismos.

16. De acordo com Almeida (1999), "a ação coletiva é resultado de uma manifestação de atores sociais ou de grupos que se constituem enquanto sujeitos coletivos" (ALMEIDA, 1999, p. 39).
Vale do Paraíso, grande cooperativa de produção de café que existia na região]. Eram cooperativas que lideravam aqui a compra, sobretudo do café, em toda a região. A cooperativa de Espera Feliz já esteve entre as 10 maiores do País. Quando iniciamos a discussão de meio ambiente, contra o uso de agrotóxicos, nós batemos de frente com esse modelo de cooperativa [referindo-se à Coapav], pois além de ela comprar os produtos, ela vendia agrotóxicos na região. Na década de 1990 em diante começamos a discutir que esse modelo de cooperativa não atendia a realidade dos trabalhadores, sobretudo dos agricultores familiares, e surgiu um boato de que essa cooperativa estava quebrando. Quando essa cooperativa quebra, nós alavancamos a discussão de nossa cooperativa. Encontramos alguns entraves, porque quando conversávamos com alguns sócios do sindicato que eram sócios da cooperativa que quebrou ficavam dizendo, mas nós vamos ser sócio (sic) da cooperativa? E começaram a ficar meio ressabiados. Fizemos um processo de formação no início, visitamos outras experiências de cooperativismo na região. Com influência do STR, associação regional, CTA.

Um ponto importante a se considerar é o fato de a região não possuir um histórico favorável quanto à formalização de cooperativas. $\mathrm{O}$ fracasso da Coavap ${ }^{17}$ na década de 1980 pode ter gerado dificuldades para outras experiências cooperativas no município, e não foi diferente para o caso da Coofeliz. Problemas para constituir um bom número de associados e, consequentemente, um volume de produção, podem se explicar parcialmente pelo fracasso da cooperativa anterior.

17. A Coavap possuía 5.400 cooperados e abrangia uma área de 48 municípios. Em relatório de avaliação do Programa de Desenvolvimento Rural Integrado da Zona da Mata (Prodemata), realizado pela Universidade Federal de Viçosa em 1986, a Coavap é destacada por trazer grandes benefícios econômicos e associativos à região. A cooperativa esteve envolvida no escândalo do desaparecimento de sacas de café nos anos 2000. Em auditoria realizada em 2001, a cooperativa apresentava uma dívida de $\mathrm{R} \$$ 20.000.000,00. Havia desaparecido do seu depósito, em Espera Feliz, mais de 216.000 sacas de café de propriedades dos associados (Relatório Final da CPI do café publicado no Diário do Legislativo de 18 de dezembro de 2004, p, 64, Vol. 2 à p. 69, Col. 1). 
240 - Relações e Estratégias de (Des)envolvimento Rural: políticas públicas, agricultura familiar e dinâmicas locais no município de Espera Feliz (MG)

Por outro lado, o envolvimento dos agricultores familiares, hoje sócios da Coofeliz, no processo de constituição da Coavap, pode ter gerado o que Hirschman (1987, p. 34) denomina de mutação $e$ conservação da energia social, em que "a primeira participação em ação pública de um tipo leva mais tarde à participação em empreendimentos coletivos de natureza diferente."

Outra experiência cooperativista que ocorreu na década de 1990 na Zona da Mata mineira, incluindo o município de Espera Feliz, foi o cooperativismo de crédito da agricultura familiar e economia solidária ${ }^{18}$. As próprias políticas públicas que surgiram nessa época, em especial o Pronaf, propiciaram novas dinâmicas financeiras nas economias locais que serviram de base para a viabilização desse novo ramo cooperativista na região. No município, as discussões acerca do cooperativismo de crédito solidário emergiram em junho de 2002, a partir de uma política de incentivo ao cooperativismo de crédito, mobilizada pela Agência de Desenvolvimento Solidário $(A D S)^{19}$. Trata-se de uma ação coletiva que tem o crédito como instrumento gerador do desenvolvimento local, porém, estritamente vinculado a marcos jurídicos que permitiam e até estimulavam esse tipo de organização.

Essas iniciativas incitadas pela ADS se edificaram nas experiências de crédito rotativo que já vinham sendo desenvolvidas na região da Zona da Mata mineira com o apoio do CTA. Após longo processo de mobilização, durante aproximadamente dois anos, foram constituídas uma cooperativa no município de Araponga, em novembro

18. As cooperativas de crédito solidário surgiram como iniciativas de movimentação financeira para a agricultura familiar com o objetivo de fornecer crédito voltado à realidade desse segmento específico. Apesar de serem instituições financeiras, se diferenciam dos bancos convencionais pelo fato de seus clientes serem também os seus donos e por apresentarem uma relação horizontal baseada na confiança e solidariedade (FREITAS et al., 2009).

19. É uma organização criada em parceria entre a Central Única de Trabalhadores (CUT), Unitrabalho e Dieese, articulada com diversas outras entidades nacionais e regionais, com o apoio de entidades de cooperação internacional (BITTENCOURT, 2001) de 2004, e outra no município de Tombos, em fevereiro de 2005. Em Espera Feliz foi criado um Posto de Atendimento Cooperativo (PAC), ligado ao sistema Ecosol (coordenado nacionalmente pela ADS), que fornecia aos agricultores familiares do município todos os serviços disponíveis. Após a constituição das cooperativas, criou-se uma nova associação com a função de servir como uma base de serviços da Ecosol em Minas Gerais, para dar suporte técnico (jurídico, contábil, elaboração de projetos etc.) às cooperativas de crédito recém-criadas. Do mesmo modo que ocorreu com a criação da Coofeliz, a constituição da Ecosol pode ser analisada como a institucionalização de uma atividade de crédito, baseada na confiança e solidariedade, em uma instituição financeira formal.

Percebeu-se, nas atas de reuniões do STR de Espera Feliz analisadas nesta pesquisa, que a discussão do cooperativismo de crédito envolveu desde a construção de processos de mobilização para a constituição da cooperativa à elaboração de estratégias para atender às metas do Banco Central. Nesse caso, o esforço foi atribuído a uma rede de relações sociais e a uma interação com outras organizações para cumprir com a exigência imposta pelas metas. Essas modificações nas dinâmicas locais causadas pela formalização das atividades desenvolvidas em torno do crédito permitem inferir que, além de complementaridade, existiu uma relação de dominação normativa dos marcos jurídicos regulatórios sobre os dispositivos coletivos utilizados pelos agricultores.

Nesse novo arranjo organizacional, percebeu-se a existência de uma forte interação entre a Coofeliz e o conjunto de organizações locais com as políticas públicas. Essas relações foram marcadas por uma tentativa de interação entre as principais organizações locais da agricultura familiar (Ecosol, Coofeliz e Asimaf) com novas formas de ação coletiva. Verificou-se que o quadro social do conjunto das organizações locais era o mesmo, ou seja, em todas as organizações, a base associativa era a mesma. Os agricultores que eram diretores de uma organização eram também sócios de 
todas as outras, sendo, algumas vezes, diretores de duas organizações.

É possível inferir que existe uma rede social ${ }^{20}$ da qual emergem essas formas de organização econômica coletiva e a orientação das atividades econômicas direcionadas a um projeto de desenvolvimento rural calcado por princípios sustentáveis (agroecologia). Dessa forma, tem-se que existe um conjunto de relações sociais e práticas coletivas preestabelecidos nas realidades em que as políticas públicas incidem, estabelecidas a partir de uma "proximidade social" capaz de gerar uma forma de coordenação dos atores sociais voltadas para processos inovadores de desenvolvimento (ABRAMOVAY, 2000, p. 397). Essas relações possibilitaram criar os mecanismos que garantiram o acesso a determinadas políticas públicas pelos atores locais.

A proximidade com os mediadores sociais também apresenta elementos importantes. No caso da Empresa de Assistência Técnica e Extensão Rural do Estado de Minas Gerais (Emater-MG), o envolvimento ocorreu com o técnico, possibilitando uma interação interpessoal, e não somente uma relação de assistência técnica com vistas a potencializar as atividades desenvolvidas pelo conjunto de agricultores familiares sócios das organizações. A partir do depoimento dos agricultores, percebeu-se que a Coofeliz e a Asimaf eram importantes instrumentos de acesso às políticas públicas, ou seja, dispositivos coletivos estabelecidos a partir do STR para o acesso a determinados serviços públicos. Essa relação demonstra que a interação direta com outros mediadores sociais pode ser estabelecida à medida que ocorria o acesso a alguma política pública pelo STR ou alguma organização que compõe essa rede social, estabelecendo vínculos de complementaridade ${ }^{21}$

20. O conceito de rede social é entendido como um conjunto de relações entre as quais existem vínculos, e sob as quais se edificam representações analíticas acerca dos "padrões de relações" estabelecidos em determinadas "situações sociais" (MARQUES, 2009).

21. O termo complementaridade será utilizado para qualificar as relações entre políticas públicas e as dinâmicas locais. De acordo com Sabourin (2009), existe uma complementaridade quando os apoios públicos potencializam
(SOUBORIN, 2009) com a orientação de desenvolvimento rural (como ocorre com a agroecologia) por parte das organizações.

\section{Evidências de mudanças a partir do acesso a políticas públicas}

A relação entre as políticas públicas federais - com suas respectivas diretrizes traçadas em termos nacionais - e as dinâmicas locais no município de Espera Feliz permitem estabelecer categorias analíticas que expressam as mobilizações e esforços realizados no âmbito do STR para executá-las, podendo extrapolar a análise para além do âmbito local. A partir do trabalho de campo foram identificadas três políticas públicas que proporcionam uma base empírica de análise: o Programa Nacional de Fortalecimento da Agricultura Familiar (Pronaf), o Programa de Aquisição de Alimentos (PAA) e o Programa Nacional de Crédito Fundiário (PNCF).

Os procedimentos de acesso ao crédito do Pronaf podem ser descritos resumidamente em três pontos principais: i) o fornecimento da Declaração de Aptidão ao Pronaf (DAP), por intermédio da Empresa de Assistência Técnica e Extensão Rural (Emater) e do Sindicato de Trabalhadores Rurais (STR); ii) a elaboração do projeto de crédito pela Emater, às vezes com apoio do técnico do próprio STR; iii) a avaliação do crédito pelos bancos, que pode seguir padrões diversos conforme seus critérios. As diretrizes de acesso são estabelecidas em nível nacional e lançadas anualmente pelo governo federal no Plano Safra da Agricultura Familiar. ${ }^{22}$

Em Espera Feliz, parte dos procedimentos de acesso do Pronaf começaram a se inserir no cotidiano do STR a partir de 2005. Até então, as organizações responsáveis em ordenar os mecanismos de acesso eram a Emater e o Banco do Brasil. A Emater emitia a DAP e elaborava os projetos, e

as dinâmicas locais, ou seja, quando o acesso à determinada política promove uma mudança positiva nas ações já desenvolvidas pelos agricultores.

22. Mais informações sobre os critérios e as normas do Pronaf em: www.mda.gov.br. 
242 - Relações e Estratégias de (Des)envolvimento Rural: políticas públicas, agricultura familiar e dinâmicas locais no município de Espera Feliz (MG)

o gerente do Banco do Brasil aprovava o projeto e liberava os financiamentos. Entretanto, havia conflitos envolvidos na elaboração dos contratos. Muitos contratos eram feitos pelos patrões, mas em nome dos meeiros, que assumiam a dívida. Sendo assim, o STR resolveu assumir parte dos procedimentos, como afirma uma agricultora:

"[...] o pessoal não concordava muito, achava que (a Emater) ficava longe do agricultor, às vezes usava o nome do meeiro, mas quem utilizava o dinheiro era o proprietário. Como acabar com isso? Então vamos trazer o Pronaf para dentro do STR. A princípio, a ideia era boa, aí nós entramos em contato com o gerente do Banco do Brasil".

Essa relação operacional do sindicato com a política gerou a necessidade de aprendizado dos procedimentos de acesso. Assim, assumir os procedimentos burocráticos de parte do acesso ao Pronaf pode ser considerado uma estratégia do STR para superar uma dificuldade encontrada pelos agricultores frente aos bancos, durante a aprovação dos projetos. Essa dificuldade é explicitada em entrevista, na qual um agricultor afirmou que:

"[...] o Pronaf é muito bom, é uma das principais linhas de crédito da agricultura familiar, com juros muito bons, principalmente depois do governo Lula, se abriu muitas portas. Apesar de que as dificuldades ainda estão na barreira que os bancos colocam [para o acesso dos agricultores ao Programa]".

Essa barreira para a liberalização deve-se ao fato de os bancos serem "generalistas, que só aceitam aplicar o crédito ao pequeno produtor em troca de garantias e de remuneração de seus serviços de extensão ultrapassados que carecem de meios suficientes" (SABOURIN, 2009, p. 144). Esse problema se complica ainda mais quando uma linha de crédito específica - como o Pronaf Agroecologia $^{23}$ - é solicitada. Essa discussão apa-

23. Linha diferenciada do Pronaf criada em 2003 para o financiamento de investimentos em sistemas de produção agroecológicos ou orgânicos, incluindo-se os custos relativos à implantação e manutenção do empreendimento. rece nas atas de reunião do STR da seguinte maneira: "[...] em relação ao Pronaf Agroecologia, o banco ainda não liberou o dinheiro; ou quando é liberado tem uma fiscalização mais rígida do que linhas de crédito comum - Pronaf Agroecologia os fiscais já estão fazendo visitas nas propriedades, e aquele que não conclui o projeto está sendo chamado para ir ao banco" (Ata de reunião de diretoria do STR de 2004). Tem-se aqui outra qualificação da relação entre as políticas públicas e as dinâmicas locais, qual sejam, as dificuldades e tensões $^{24}$ provocadas nas dinâmicas locais à medida que se percorrem os mecanismos de acesso ao Pronaf.

Em relação ao PAA, os procedimentos de acesso exigem a elaboração de um projeto e uma organização social capaz de executar o programa. Em Espera Feliz, o primeiro acesso aconteceu em 2006 e envolvia cerca de 30 famílias. O valor do primeiro projeto era de aproximadamente $\mathrm{R} \$$ 40.000. Já o segundo projeto submetido envolveu 110 famílias, com valor total de R 373.000 . $\mathrm{O}$ acesso a esse programa gerou mudanças, em termos locais, no sentido da adequação das estruturas organizativas locais aos procedimentos necessários de execução do mesmo (SILVA e SILVA, 2011). A entrevista concedida por um agricultor que acompanhou o processo de acesso ao PAA também apresenta questões relacionadas às dificuldades de operação do programa:

"[...] por mais que o Lula fez as coisas (sic), a estrutura ainda é bem engessada, muita burocracia, bem intencionada ou não, acaba ficando preso (sic) nessas coisas. Próprio PAA, por exemplo, acaba dando um trabalho grande. A gente não consegue assumir de verdade. Pois um projeto do tamanho desse quem é que pode assumir. Não tem liberação para isso, e quando tem existe uma exigência a mais. A estrutura ainda é bem centralizada.

24. De acordo com Sabourin (2009), as dificuldades e tensões se referem às descontinuidades de apoio, caracterizadas pelas defasagens entre os ritmos e prazos das organizações locais e dos gestores dos programas. Outros fatores como o pouco envolvimento dos órgãos públicos e a falta de competência para executar determinados programas também são componentes dessa relação. 
Falta pensar em uma estrutura diferente. Se houvesse maior envolvimento da base, tiraria o trabalho de alguém".

Essa dinâmica exigiu da organização que operava o programa uma racionalidade econômica suficientemente aguçada para garantir a produção, a entrega dos produtos e o pagamento nos prazos estabelecidos no projeto. Esses problemas são evidenciados no seguinte relato:

"Uma coisa é falar que vai produzir, agora se não tiver a meta do que vai produzir não consegue entregar os produtos no prazo. Nós, agricultores, somos muito relaxados, a gente quer produzir no tempo que quer, enquanto se tem uma escala não é no tempo que eu quero, é no tempo que é preciso [aquele definido no projeto]".

Pode-se perceber que o acesso ao PAA também gerou uma relação baseada em dificuldades e tensões. Mesmo com todas as dificuldades de ser operado, o programa evidenciou o esforço do STR junto aos seus sócios no que se refere ao tema da comercialização.

Já em relação ao PNFC, de acordo com o agricultor familiar responsável pela execução do programa no STR, havia, na época da realização da pesquisa, 52 famílias com escritura da terra e mais ou menos 80 famílias em processo de obtenção do benefício. O STR exerceu papel fundamental como organização responsável em capitanear a PNCF para o município. Ele está presente em todos os trâmites necessários para a liberação do financiamento para as famílias. $\mathrm{O}$ acesso a esse programa estabeleceu, portanto, uma relação de complementaridade, na medida em que o acesso à terra esteve vinculado a um conjunto de ações que foram desenvolvidas pelo STR junto à base social que ele representava, como afirmou um agricultor em entrevista:

"Se souber trabalhar agora, daqui uns anos o pessoal consegue pagar a terra. Se houver diversificação da produção é o ideal. Montar pequenas agroindústrias na comunidade para agregação de valor é uma alternativa [...] se pudermos trabalhar em uma terra produtiva como é a nossa, e com essas oportunidades de comercialização, acho que a oportunidade de comprar e pagar a terra está assegurada".

O STR, enquanto entidade responsável pelo PNCF em Espera Feliz, teve que percorrer alguns caminhos institucionais de relação com a prefeitura para estabelecer aprovação dos projetos, que foram encaminhados para aprovação na Câmara Técnica em Belo Horizonte. Nesses caminhos estabeleceu-se a relação de dificuldades e tensões, como pode ser identificado a partir da fala de um agricultor que era membro do Conselho Municipal de Desenvolvimento Rural Sustentável (CMDRS) do município: “O Crédito Fundiário também era discutido (nas reuniões do CMDRS). A primeira aprovação era uma briga danada. A gente colocava em pauta e o poder público não queria de jeito nenhum. Para aprovar a primeira remessa não foi fácil e foi via STR".

O aumento das atividades do STR e o volume de trabalhos provocaram mudanças nas discussões das reuniões, sendo essas voltadas cada vez mais para a execução das políticas públicas. Com base nas atas de reuniões, percebeu-se claramente essa mudança. Expressões como "formação sindical", "conscientização política", "mobilização nas comunidades", passaram a ser recorrentes a partir do início da década de 1990. A partir de 1994, as pautas das reuniões têm um caráter mais operacional, sendo que as discussões se dão muito mais em torno da execução e dos trâmites burocráticos das políticas públicas acessadas e do funcionamento das novas organizações (cooperativas), do que em torno da formação e trabalhos comunitários com os agricultores.

Apesar de terem emergido novas organizações com o propósito de suprir temas específicos, a estrutura de trabalho que prevaleceu continuava sendo a vinculada ao STR, como um agricultor afirmou em entrevista: "As pessoas fazem parte de várias entidades, o STR é a mãe de todos. Se não for o STR, as outras organizações têm dificuldades para caminhar". As organizações acessam determinada política para potencializar algumas 
244 - Relações e Estratégias de (Des)envolvimento Rural: políticas públicas, agricultura familiar e dinâmicas locais no município de Espera Feliz (MG)

atividades que já estão sendo desenvolvidas no município, como expressado por um agricultor: "eu acho o seguinte, não que [as ações] tenha (sic) partido dessas políticas, mas colaborou (sic). Eu acho que é as duas partes (sic), você tem as alternativas e você se depara com uma política pública que vai te ajudar".

A Figura 1 é uma tentativa de sintetizar esquematicamente esse conjunto de processos no sindicalismo rural de Espera Feliz em suas relações com as políticas públicas. Nela, é possível identificar que, no período entre as décadas de 1970 e 1990, a orientação das ações governamentais estavam ancoradas, predominantemente, em políticas voltadas para a modernização da agricultura. Frente a esses processos, emergiram organizações dos trabalhadores rurais com pautas de reivindicações específicas, voltadas para salvaguardar os direitos sociais dos trabalhadores rurais, dentre elas, o próprio sindicato dos trabalhadores rurais de Espera Feliz. A partir da década de 1990, como visto anteriormente, a agricultura familiar entra em cena como força social e política em busca de sua inserção na agenda governamental. As mobilizações sociais se ampliaram, abarcando, além de sindicatos, associações e cooperativas. Esse fenômeno também foi observado em Espera Feliz com o surgimento de novas organizações de agricultura familiar no âmbito do STR. As orientações das ações coletivas passaram a envolver questões relacionadas com a organização produtiva, comercialização, crédito etc. Nesse conjunto de relações, foram estabelecidas interações diversas entre as políticas públicas de desenvolvimento rural e as dinâmicas locais, exigindo que os mediadores sociais passassem a assumir outros papéis.

Nesse sentido, as políticas acessadas incidiram em uma rede social na qual havia interesses comuns e leituras da realidade que eram conver-

Figura 1. Processos desencadeados pelo Sindicato de Trabalhadores Rurais de Espera Feliz Contexto das políticas públicas

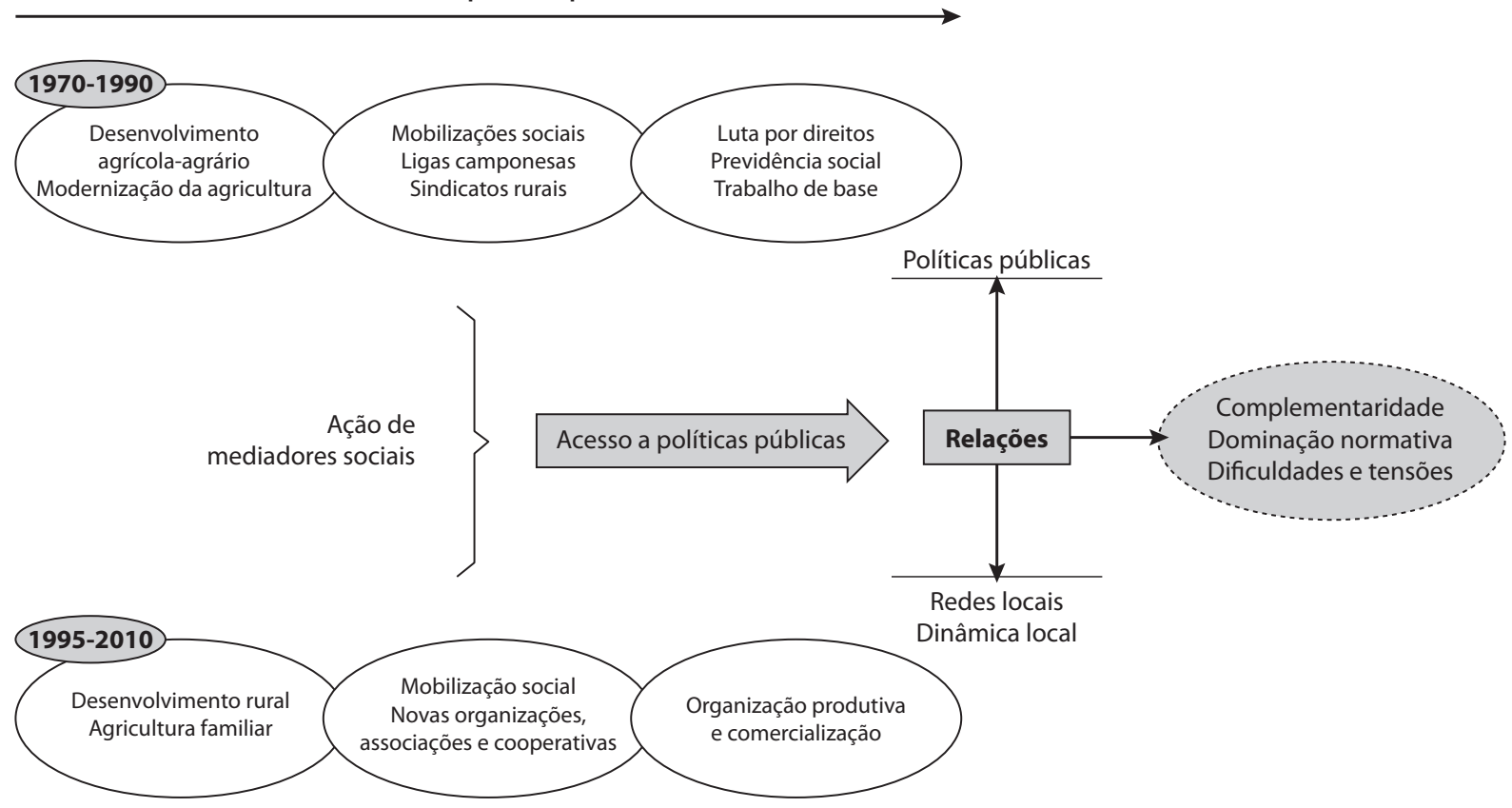

Agricultura familiar na agenda das políticas públicas

Fonte: Elaboração dos autores. 
gentes. Esses interesses foram demonstrados a partir da formalização dos dispositivos coletivos dos agricultores e da edificação de novas organizações de agricultura familiar nesses dispositivos. Existe uma rede de indivíduos, empoderados e organizados, que constitui o tipo de organização necessária (sindicato, associação, cooperativa de crédito ou de comercialização) para resolver problemas referentes a cada contexto. Todas as organizações estabeleceram uma espécie de polimorfismo organizacional para garantir seu acesso às políticas públicas acessadas.

No entanto, o grande esforço do STR na execução das políticas públicas para sua base social, políticas estas fruto de um longo histórico de lutas do movimento sindical brasileiro, comprometeu, por outro lado, sua capacidade de desenvolver outros projetos na região; ou a luta por outras demandas dos trabalhadores, tornando-o refém da agenda de Estado. Esse fenômeno é identificado na trajetória do STR de Espera Feliz, e pode ser sintetizado na expressão de um agricultor sindicalista, que afirmou o seguinte:

"O sindicato [...] tem um conjunto de trabalhos e um deles inclui a questão das políticas públicas, o acesso do agricultor às políticas públicas, principalmente o Pronaf, previdência social, são políticas que o sindicato sempre lutou para que o agricultor tivesse acesso. Mas essas políticas entraram para dentro (sic) do sindicato, e faz (sic) com que o sindicato acabe fazendo um papel do Estado, isso acaba implicando um pouco nas bandeiras de luta, porque fica um acúmulo de trabalho de fazer o trabalho de Estado e acaba deixando de investir em pessoas que são lideranças para fazerem isso e restringem as bandeiras de luta".

Portanto, pode-se perceber que, apesar das diversas relações (positivas ou não) que foram estabelecidas a partir da interação com as políticas públicas e as dinâmicas locais, existiu uma mudança nítida na prática sindical relacionada diretamente com essas políticas de desenvolvimento rural, ora limitando, ora potencializando as ações estabelecidas no nível local.

\section{Considerações finais}

A partir do histórico do Sindicato de Trabalhadores Rurais do município de Espera Feliz, é possível identificar a relação de mudança no nível local no mesmo período de mudanças no contexto das políticas de desenvolvimento rural no cenário nacional. São períodos bem marcados no final da década de 1980, com temas relacionados à assistência social, que transitam para temas relacionados às questões produtivas e de organização econômica, a partir de meados da década de 1990. Nesse período, se constituíram novas organizações da agricultura familiar no município, com diferentes objetivos. A emergência dessas organizações evidencia a incorporação de diretrizes e políticas em termos locais, provocando mudanças na prática sindical, em particular, e na ação coletiva desses atores locais, de maneira geral.

Com base na análise apresentada, percebeu-se que existiam dispositivos coletivos utilizados pelos agricultores como estratégia de ação coletiva. Esses dispositivos enfrentaram uma adaptação em suas regras de reciprocidade, passando a constituir estruturas institucionais formalizadas, tais como a Asimaf, Coofeliz e Ecosol, na medida em que se relacionavam com as políticas públicas de desenvolvimento rural que foram surgindo na agenda governamental. O contexto de surgimento dessas organizações, no âmbito do STR, é um componente explicativo da relação entre as mudanças nas políticas públicas de desenvolvimento rural e as dinâmicas locais.

Contudo, apenas o surgimento de uma política pública não explica a criação desses mecanismos. Entende-se que essas políticas, quando acessadas, encontram um conjunto de experiências prévias, que geram processos coletivos de aprendizagem capazes de viabilizar ações de desenvolvimento orientadas, de modo mais próximo e coerente, por demandas do universo da agricultura familiar. Destarte, existe uma organização social prévia sob a qual as relações externas incidem como complementaridade dessas ações locais. 
246 - Relações e Estratégias de (Des)envolvimento Rural: políticas públicas, agricultura familiar e dinâmicas locais no município de Espera Feliz (MG)

As relações estabelecidas com as políticas públicas de desenvolvimento rural ocorrem de diferentes maneiras, desde relações de complementaridade, passando por relações de dominação normativa e chegando a dificuldades e tensões. No caso da relação de complementaridade, o acesso à determinada política pública promove uma mudança positiva nas ações já desenvolvidas pelos agricultores. Em relação à dominação normativa, o acesso a determinados programas pode gerar mudança em termos locais no sentido da adequação das estruturas organizativas locais aos procedimentos necessários de execução do programa. Já quanto às dificuldades e tensões, fica expressa a descontinuidade entre a orientação das diretrizes de programas específicos e os mediadores sociais responsáveis por sua execução.

Nesse conjunto de relações, vão se forjando aproximações entre as organizações e entre os mediadores sociais que atuam no município. Esses mediadores, no caso de Espera Feliz, estiveram presentes na criação dessas organizações. No entanto, a relação com os mediadores também pode ser conflituosa, na medida em que a aproximação pode eventualmente divergir das orientações coletivas para o desenvolvimento que os agricultores têm.

Como resultado de todos esses processos que se entrelaçam no plano local, verificou-se a existência de uma mudança na prática sindical a partir da emergência de novos temas e da constituição de uma organização responsável por uma atividade econômica. Essas mudanças se relacionam com as transformações no contexto geral do sindicalismo rural brasileiro, com a inserção da agricultura familiar na agenda de políticas públicas e com o cotidiano de gestão de uma estrutura constituída para execução de programas e projetos específicos.

\section{Referências bibliográficas}

ABRAMOVAY, R. O capital social dos territórios: repensando o desenvolvimento rural. Revista de Economia Aplicada, v. 4, n. 2, 2000.
ADH. Atlas do Desenvolvimento Humano. Disponível em: $<$ http://www.pnud.org.br>. Acesso em: 14 mai. 2011.

ALMEIDA, J. A construção social de uma nova agricultura: Tecnologia Agrícola e movimentos sociais no sul do Brasil. Porto Alegre: Ed. Universidade/URGS, 1999.

BITTENCOURT, G. A. Cooperativas de crédito solidário. Estudos NEAD, n. 4, 2001.

BONETTI, L. W. Políticas Públicas por dentro. 2. ed. Ijuí: Ed. Unijuí, 2007.

BONI, V. Poder e Igualdade: As relações de gênero entre sindicalistas rurais de Chapecó, Santa Catarina. Revista Estudos Feministas, Florianópolis, v. 12, n. 1, 2004.

CINTRÃO, R. P. ONGs, tecnologias alternativas $e$ representação política do campesinato: uma análise da relação entre o Centro de Tecnologias Alternativas e os Sindicatos dos Trabalhadores Rurais na Zona da Mata Mineira. Dissertação de Mestrado: Universidade Federal Rural do Rio de Janeiro - Curso de PósGraduação em Desenvolvimento Agrícola, 1996.

COMPANHIA NACIONAL DE ABASTECIMENTO (CONAB). Programa de Aquisição de Alimentos - PAA. Disponível em: <http://www.conab.gov.br>. Acesso em: jan. 2010.

CORDEIRO, Â., SCHMITT, C. J. e ARMANI, D. Organizações Sociais rurais diante do ajuste: o caso do Brasil. Mimeo, 2003.

D'ÁVILA, C. A. R. e SILVA, S. P. Segurança alimentar e desenvolvimento local: uma análise dos resultados do Programa de Aquisição de Alimentos (PAA) em Minas Gerais. Revista de Politicas Públicas, v. 15, n. 2, 2011.

DIAS, M. M. As ONG's e a construção de alternativas para o desenvolvimento rural: um estudo a partir da Assessoria e Serviços a Projetos em Agricultura Alternativa (AS-PTA). 2004. Tese (Doutorado). Curso de Pós-Graduação em Desenvolvimento, Agricultura e Sociedade, Universidade Federal Rural do Rio de Janeiro, Rio de Janeiro, 2004.

FAVARETO, A. Agricultores, trabalhadores: os trinta anos do novo sindicalismo rural no Brasil. Revista Brasileira de Ciências Sociais, São Paulo, v. 21, n. 62, 2006.

FERRANTE, V. L. S. B. O estatuto do trabalhador rural e o FUNRURAL. Revista de Ciências Sociais, v. 1, 1976.

FREITAS, A. F., FREITAS, A. F, SILVA, M. G. e DIAS, M. M. Fortalecendo laços sociais e financeiros: o sistema ecosol de crédito solidário em Minas Gerais. In: Anais do Io Seminário Nacional de Sociologia Econômica, Florianópolis, 2009. 
HIRSCHMAN, A. O. O progresso em coletividade: experiências de base na América Latina. Fundação Interamericana, 1987.

KAGEYAMA, A. Desenvolvimento Rural: Conceitos e aplicações ao caso brasileiro. Porto Alegre: Editora da UFRGS: Programa de Pós Graduação em Desenvolvimento Rural, 2008.

LAMARCHE, H. (Coord.). Introdução geral. In: A agricultura familiar: comparação internacional. Campinas/SP: UNICAMP, 1993.

MARQUES, E. C. L. As Redes importam para o acesso a bens e serviços obtidos fora de mercados? Revista Brasileira de Ciências Sociais, v. 24, n. 71, 2009.

MARTINS, J. de S. A chegada do estranho. São Paulo: HUCITEC, 1993.

NEVES, D. P.ODesenvolvimento de uma outra agricultura: o papel dos mediadores sociais. In: FERREIRA, A. D. D. e BRANDENBURG, A. (Orgs.). Para pensar outra agricultura. 2. ed. Curitiba: Editora UFPR, 2008.

PLOEG, J. D. Van Der. Desenvolvimento rural: expressões européias d recampesinização. In:

Camponeses e impérios alimentares: lutas por autonomia e sustentabilidade na era da globalização. Porto Alegre: Editora da UFRGS, 2008.

RODRIGUES, A. S. A federação dos trabalhadores na agricultura familiar: um novo sindicalismo em construção. Curitiba: UFPR, 2004. Dissertação de Mestrado em Sociologia - Universidade Federal do Paraná, 2004.

SABOURIN, E. et al. O Reconhecimento Público dos Atores Coletivos da Agricultura Familiar no Nordeste. Cadernos de Ciência E Tecnologia, Brasília, v. 22, n. 2, 2005.
SABOURIN, E. Camponeses do Brasil. Rio de Janeiro: Garamond, 2009.

SCHNEIDER, S. Tendências e Temas dos Estudos Sobre desenvolvimento Rural no Brasil. Versão ampliada do trabalho Trends and matters in rural development studies in Brazil. Anais do XXII congresso $f$ the European Society for rural Sociology, Wageningen, Holanda, 2007.

- A pluriatividade na agricultura familiar. Porto Alegre: UFRGS, 2003.

SILVA, S. P. Território e estruturas de mercado para produtos tradicionais: o caso da produção familiar de cachaça no território Alto Rio Pardo (MG). Revista Isegoria, n. 02, 2012.

Políticas públicas, agricultura familiar e desenvolvimento territorial. Revista Cadernos Gestão Pública e Cidadania, v. 16, n. 58. FGV: São Paulo, 2011.

SILVA, M. G. e SILVA, S. P. Para além do acesso: uma análise da relação entre mercados institucionais e empreendimentos de economia solidária no meio rural. Boletim Mercado de Trabalho, n. 49, Ipea, 2011.

SOUZA, E. F. M., SILVA, M. G. e SILVA, S. P. A cadeia produtiva da mandiocultura no Vale do Jequitinhonha (MG): aspectos sócio-produtivos e geração de renda para a agricultura familiar. Revista Isegoria, n. 02, 2012.

SOUZA, C. Políticas Públicas. Revista Sociologias, Porto Alegre, ano 8, n. 16, 2006.

WANDERLEY, M. de N. B. Raízes históricas do campesinato brasileiro. In: Anais do XX Encontro Anual da ANPOCS. Caxambu, MG, 1996. 
